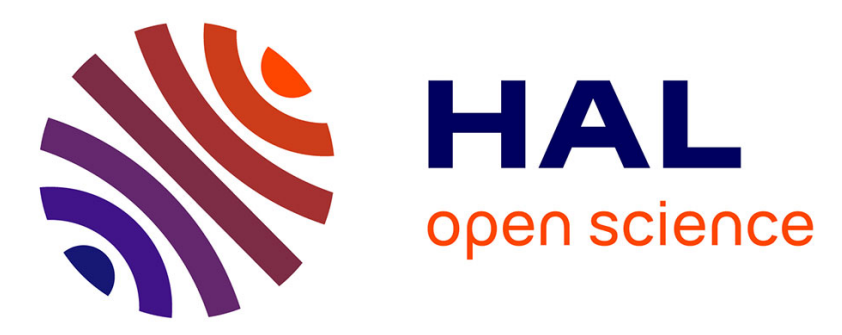

\title{
Investigation of tool deflection during milling of thread in Cr-Co dental implant
}

Anna Carla Araujo, Guillaume Fromentin

\section{To cite this version:}

Anna Carla Araujo, Guillaume Fromentin. Investigation of tool deflection during milling of thread in Cr-Co dental implant. International Journal of Advanced Manufacturing Technology, 2018, 99 (1-4), pp.531-541. 10.1007/s00170-018-2520-x . hal-02060570

\section{HAL Id: hal-02060570 https://hal.science/hal-02060570}

Submitted on 8 Apr 2019

HAL is a multi-disciplinary open access archive for the deposit and dissemination of scientific research documents, whether they are published or not. The documents may come from teaching and research institutions in France or abroad, or from public or private research centers.
L'archive ouverte pluridisciplinaire $\mathbf{H A L}$, est destinée au dépôt et à la diffusion de documents scientifiques de niveau recherche, publiés ou non, émanant des établissements d'enseignement et de recherche français ou étrangers, des laboratoires publics ou privés. 


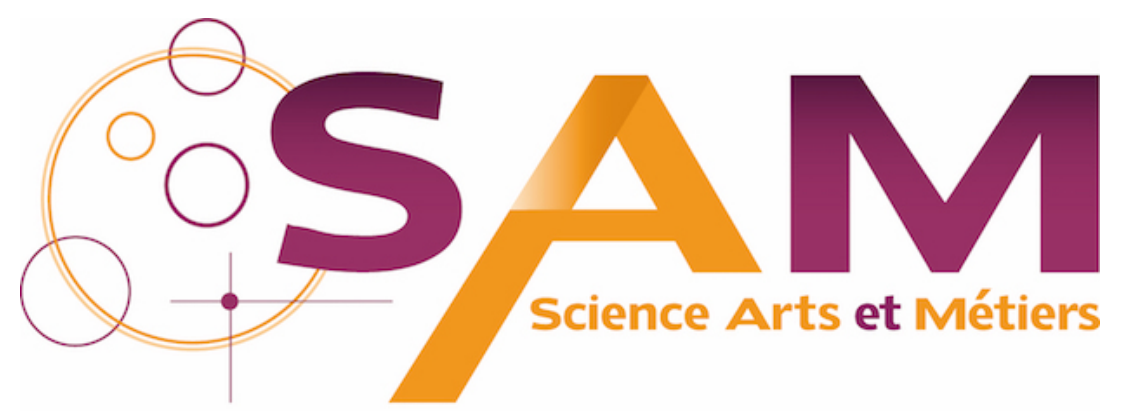

Archive Ouverte - Open Repository

\section{Science Arts \& Métiers (SAM)}

is an open access repository that collects the work of Arts et Métiers ParisTech researchers and makes it freely available over the web where possible.

This is an author-deposited version published in: https://sam.ensam.eu Handle ID: .http://hdl.handle.net/10985/14615

\section{To cite this version :}

Anna Carla ARAUJO, Guillaume FROMENTIN - Investigation of tool deflection during milling of thread in Cr-Co dental implant - The International Journal of Advanced Manufacturing Technology - Vol. 99, n¹-4, p.531-541 - 2018 


\title{
Investigation of tool deflection during milling of thread in $\mathrm{Cr}$-Co dental implant
}

\author{
Anna Carla Araujo ${ }^{1}$. Guillaume Fromentin ${ }^{2}$
}

\begin{abstract}
Milling is a good option for manufacturing internal threads in hard-to-cut dental components due to lower cutting forces. In the case of a very small drilled diameter, the tool cannot be large enough to reduce tool deflection nor sufficiently small to avoid the influence of the tool penetration. As a consequence, both situations need to be considered and no other research study dealt with this aspect for the modeling of thread milling forces. This article deals with the analysis of forces, deflection, and undercutting during machining of one typical internal thread geometry used for implants in a chrome-cobalt dental alloy. The geometry is analyzed considering the influence of tool penetration and it is presented new equations to identify the regions where it occurs. Machining experiments are conducted acquiring cutting forces and tool axis position in order to calculate the tool radial forces and estimate tool deflection. Manufactured threads geometry is measured to evaluate dimension quality. It can be claimed that the tool trajectory should consider one extra revolution around the drilled hole in order to machine the undercut material due to tool deflection for this small tool diameter.
\end{abstract}

Keywords Thread milling $\cdot$ Dental alloy $\cdot$ Thread accuracy $\cdot$ Chrome-cobalt $\cdot$ Tool deflection

\section{Nomenclature}

$D \quad$ Nominal thread diameter $(\mathrm{mm})$

$D_{1} \quad$ Drilled diameter and Internal thread diameter ISO 68-1 (mm)

$D_{t} \quad$ Tool envelop diameter described by the front cutting edge $(\mathrm{mm})$

$D_{t t} \quad$ Diameter of the tool axis trajectory during full machining $(\mathrm{mm})$

$P \quad$ Thread pitch (mm)

$n_{p} \quad$ Number of machined threads at the same time

$n_{p}^{\max } \quad$ Maximum number of machined threads

$a_{d o c}(t) \quad$ Axial depth of cut (mm)

$a_{d o c}^{\max } \quad$ Maximum axial depth of cut ( $\left.\mathrm{mm}\right)$

$N_{f} \quad$ Number of tool flutes

$\theta_{f} \quad$ Angle between flutes

$\lambda_{s t} \quad$ Tool helix angle

Anna Carla Araujo

anna@ufrj.br

1 Mechanical Engineering Department - Poli/COPPE,

Universidade Federal do Rio de Janeiro (UFRJ), Rio de Janeiro, Brazil

2 LaBoMaP, Arts et Metiers ParisTech, Rue Porte de Paris, 71250 Cluny, France $\theta_{t w} \quad$ Tooth working Angle

$c(t) \quad$ Cutting continuity

$N \quad$ Spindle speed (rpm)

$V_{c} \quad$ Cutting speed $(\mathrm{m} / \mathrm{min})$

$f_{t} \quad$ feed per tooth $(\mathrm{mm} / \mathrm{th})$

$f_{t x y} \quad$ feed per tooth projected in xy plane

$f_{t z} \quad$ feed per tooth projected in $\mathrm{z}$ direction

$t_{\text {cmax }} \quad$ Maximum uncut chip thickness in front cutting edge $(\mathrm{mm})$

$t, t_{1}, t_{2}$ time (s)

$r_{\text {pmax }}$ Radial penetration during full machining ( $\left.\mathrm{mm}\right)$

$r_{d o c} \quad$ Radial depth of cut $(\mathrm{mm})$

$R_{0} \quad$ Fixed Reference Frame in $\mathrm{O}$ and $\mathrm{CNC}$ tool axis coordinates: $(x \hat{(t)}, \hat{y(t)}, z \hat{(t)})$

$\mathbf{F}_{0}=\left[F_{x}, F_{y}, F_{z}\right] \quad$ Force components in $R_{0}$

$O \quad$ Drilled hole position, $R_{0}$ Referential Frame Origin

$R_{1} \quad$ Moving reference Frame centered in $O$ and tangential to workpiece surface

$\mathbf{F}_{1}=\left[F_{\text {rad }}, F_{\text {tan }}, F_{z}\right] \quad$ Force components in $R_{1}$

$R_{2} \quad$ Moving reference frame centered in tool axis and fixed in one point of the cutting flute

$\mathbf{F}_{2}=\left[F_{r}, F_{t}, F_{z}\right] \quad$ Force components in $R_{2}$ 
$\theta_{1}(t) \quad$ Angle of Tool Axis Position, angle between $R_{1}$ and $R_{0}$

$\theta_{2}(t) \quad$ Tool Revolution Angle, angle between $R_{2}$ and $R_{0}$ $(\mathrm{rad} / \mathrm{s})$

$Q, A, A_{1}, B$ : Special location points on tool axis trajectory

$P_{1}, P_{2}, P_{3}$ : $\quad$ Points in hole surface

$\beta \quad$ Angle between $\overline{O P_{2}}$ and $\overline{O A}$

$h_{p i} \quad$ Pitch height in tool, located in the $i$ thread (mm)

$h_{w p i} \quad$ Pitch height in workpiece, located in the $i$ thread (mm)

$\Delta r^{i} \quad$ Difference between thread height and radial penetration located in $i$ thread ( $\mathrm{mm}$ )

\section{Introduction}

Titanium and chrome-cobalt alloys are used for implants because it presents high corrosion resistance and strengthto-weight ratio and per its bio-compatibility [1]. Although titanium is mostly used by dentist industry, is increasing the use of chrome-cobalt alloys because it has sufficient strength to withstand the occlusal forces applied to partial denture frameworks [2]. Two-part implant systems having internal machined connection seem to offer an advantage considering failure compared to other systems [3] but it is important to optimize implant geometry to avoid part breakage during extraction by pullout procedure [4].

Different manufacturing processes can be used to produce external threads in implants: grinding, quoted as slow and inefficient, electric discharge machining, using fabricated graphite die, external whirling, with several inserts having the cutting edge geometry of the thread envelop profile. and form and cut tapping, used for internal threads. Even if the implant is produced by additive manufacturing, the internal thread should be produced by subtractive processes [5]. The typical manufacturing process used for an internal thread is forming or cut tapping [6], but there are other two options: internal whirling and thread milling. Internal whirling depends on precision multi-axis machine, with a synchronized rotation of tool and workpiece [7]. In tapping, residual stresses could be much higher if compared to thread milling or whirling. Hernandez [8] studied failure in threads due to the high-stress rate for screw manufactured by deformation processes that could produce weak regions for the structure. The internal threads produced by deformation failed catastrophically after 6 months of service due to a fracture presented at the inner screw used for fixation of the abutment. Some articles studied the optimization of the workpiece geometries, as $\mathrm{Wu}$ et al. [9], that presented the effects of thread geometry and profile on the stability of dental implants finding an optimal abutment design, with a lower resistance to initial insertion and higher stability, for final instrumentation. Also, Hasan et al. [10] analyzed fine threads and the influence of the design on loading immediately dental implants. If the geometry cannot be adapted, the manufacturing process could change to reduce the problem.

Thread milling could produce internal and external threads, especially on machining hard materials, as titanium alloys, because its feed rate could be reduced with no impact on cutting speed. In thread turning, the feed per revolution should be equal to the thread pitch and cannot be reduced [11]. Comparing to tapping, in case of a breakage, thread milling is safer because it can be removed without damage to the workpiece. Deep analysis of geometry and kinematic should be done in thread milling because the tool geometry and the helical tool trajectory are complex [12]. A geometrical model and an analytical formulation to define the local rake face on the cutting edge by Fromentin et al. [13] and it is used for calculating uncut chip thickness during internal thread milling [14]. Araujo et al. [15] used the local rake angle approach to study geometrical analysis of thread milling parameters in Ti-6Al-4V with metric threads, and an analysis of variance for determining the influence parameters and bring a physical understanding of the process and focused in finding the optimum flute angle. Wan and Altintas [16] developed a detailed analysis of the dynamics of thread milling.

A previous experimental study compared forces on the thread milling of mini-threads in titanium and chromecobalt alloy [17]. In the present article, it is done a geometrical analysis of thread milling and a tool deflection analysis in the case that the drilled hole is very close to the milling tool diameter, which was not studied before. The standard M2 thread is produced in a Chrome-cobalt commercial dental alloy Romur 400. The geometry is predicted considering the influence of tool penetration and experiments are conducted acquiring cutting forces and tool axis position in order to estimate tool deflection.

\section{Analytical formulation of influence of tool penetration in thread milling}

In thread milling, the tool travels inside a drilled hole describing a helical trajectory to manufacture the thread profile with a nominal diameter $D$. The basic analysis of the thread milling process is extensively presented by many authors $[15,18,19]$. The milling tool diameter is $D_{t}$ and the drilled diameter is $D_{1}$. The tool path is described by the CNC coordinates $(x(t), y(t), z(t))$ in the machine-tool reference frame $R_{0}$.

The tool axis position angle is calculated by $\theta_{1}(t)=$ $\arctan \frac{y(t)}{x(t)}$. The tool revolution angle $\theta_{2}(t)$ is driven by the spindle speed $N: \dot{\theta_{2}}=2 \pi N / 60$. The tool rotates 
clock-wise, so $\theta_{2}$ has opposite sense for $\theta_{1}$, in the case of down milling.

Feed per tooth $f_{t}$ is defined on the trajectory direction $f_{t}=V_{f} \cdot N_{f} \cdot N$, where $V_{f}$ is feed velocity. The feed per tooth is decomposed in $x y$ plane and in $z$ direction, as described in Eq. 1:

$f_{t}=\sqrt{f_{t z}^{2}+f_{t x y}^{2}}$

Thread milling process presents three principal stages: tool penetration, full machining (FM), and tool exit. The two first stages are presented in Fig. 1.

(i) Tool penetration: the tool moves in a half revolution penetration strategy (HRPS) [20] from the center $\mathrm{O}$ until point $\mathrm{A}$. The radial penetration increases until the desired tool engagement $r_{p}^{\max }$. The vertical displacement during tool penetration is proportional to the thread pitch: $P / 4$. For reference, the time range, from 0 to $t_{1}$, and $\theta_{1}$ range in tool penetration is defined below:

$$
t=\left[0, t_{1}\right] \rightarrow \theta_{1}(t)=\frac{\pi}{t_{1}} t-\pi \rightarrow \theta_{1}(t) \in\left\{-\pi<\theta_{1}<0\right\}
$$

(ii) Full machining: the tool is fully engaged. The nominal radial penetration is constant until there is no influence of tool penetration. The tool travels a helical trajectory where $D_{t t}$ is its diameter and the tool vertical displacement is the thread pitch $P$, if the number of threads $n_{P}$ to be machined is lower than the number of threads on the cutting edge $n_{P}^{\max }$. If not, the tool continues the helical trajectory for more then one pitch. In the case $n_{P}<n_{P}^{\max }$, the depth of cut is described by $a_{d o c}(t)=\left(n_{P}-\frac{\theta_{1}(t)}{2 \pi}\right) P$ and the time range, from $t_{1}$ to $t_{2}$, and $\theta_{1}$ range in the case is:

$$
\begin{aligned}
t & =\left[t_{1}, t_{2}\right] \rightarrow \theta_{1}(t)=\frac{2 \pi}{\left(t_{2}-t_{1}\right)} \cdot\left(t-t_{1}\right) \\
& \rightarrow \theta_{1}(t) \in\left\{0<\theta_{1}<2 \pi\right\}
\end{aligned}
$$

(iii) Tool exit: the tool goes back to the initial hole axis position as the radial penetration reduces to zero. The vertical displacement is $P / 4$. The time range, from $t_{2}$ to $t_{3}$, and $\theta_{1}$ range in tool exit is defined by:

$$
\begin{aligned}
t & =\left[t_{2}, t_{3}\right] \rightarrow \theta_{1}(t)=\frac{\pi}{\left(t_{3}-t_{2}-t_{1}\right)} \cdot\left(t-t_{2}\right) \\
& \rightarrow \theta_{1}(t) \in\left\{0<\theta_{1}<\pi\right\}
\end{aligned}
$$

\subsection{Geometrical analysis during tool penetration}

As it is shown in Fig. 1, the tool penetration trajectory is developed from $O$ to $A$. But, during this path, the tool envelope only meet the workpiece surface in point $P_{1}$ when its axis is centered in $Q$ (Fig. 2a). In this position, if one point the cutting edge is engaged and aligned with the line $\overline{O P_{1}}$, the first chip is removed. This position is calculated by Eq. 2:

$\theta_{1}(Q)=\arccos \left(\frac{D_{1}-D_{t}}{D_{t t}}\right)$

After this point, the tool removes material until its axis arrives at $A$. The area of the material removed during this stage is identified on Fig. 2a by the limit points $P_{2}$ and $P_{3}$. In order to locate the position of $P_{2}$, which it is important to analyze penetration influence on thread milling process, it is identified in Fig. 2 the angle $\beta$ between $\overline{O P_{2}}$ and $\overline{O A}$. Equation 3 calculates the value of $\beta$ :

$\beta=\arccos \left(\frac{D_{1}^{2}-D_{t}^{2}+D_{t} \cdot D_{t t}}{D_{t t} \cdot D_{1}}\right)$

\subsection{Geometrical analysis during full machining}

The tool is in full machining after passing the point $A$. During this period, it can be identified two regions: in the beginning when the nominal radial penetration is constant without any influence of tool penetration, so-called steady state, and the region where the material has already been taken by tool penetration.

The maximum uncut chip thickness $t_{c \max }$ achieved by the front cutting edge (FCE) in steady state [13] is identified Fig. 2b. In this figure, it is presented the regular radial depth
Fig. 1 Tool penetration and full machining in thread milling
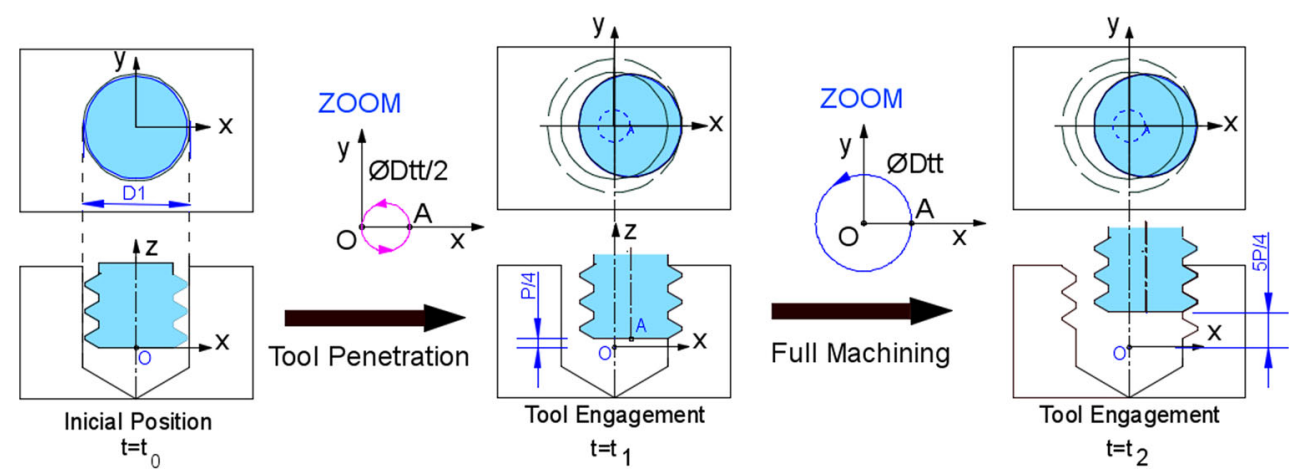


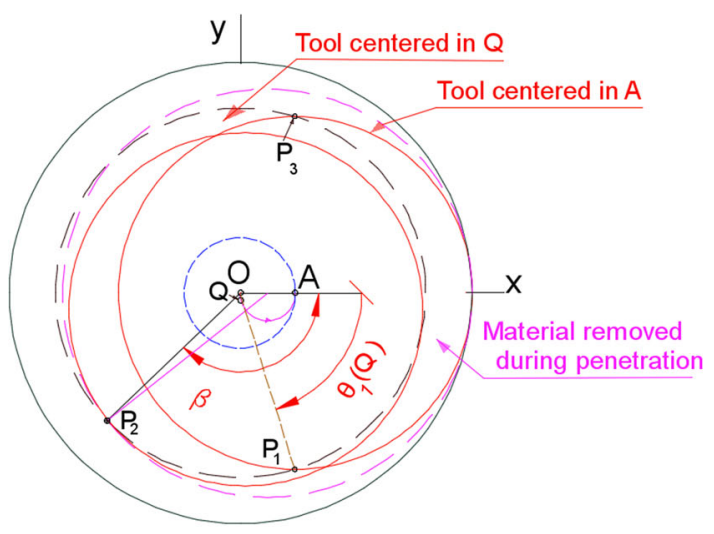

(a) Tool Penetration Geometrical Analysis

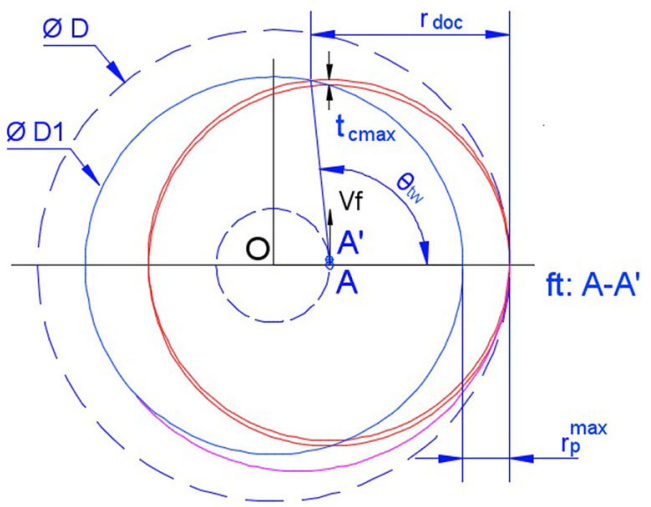

(b) Tool Centered in A (begining of full machining) and tool centered in $\mathrm{A}^{\prime}, f_{t}=A A^{\prime}$

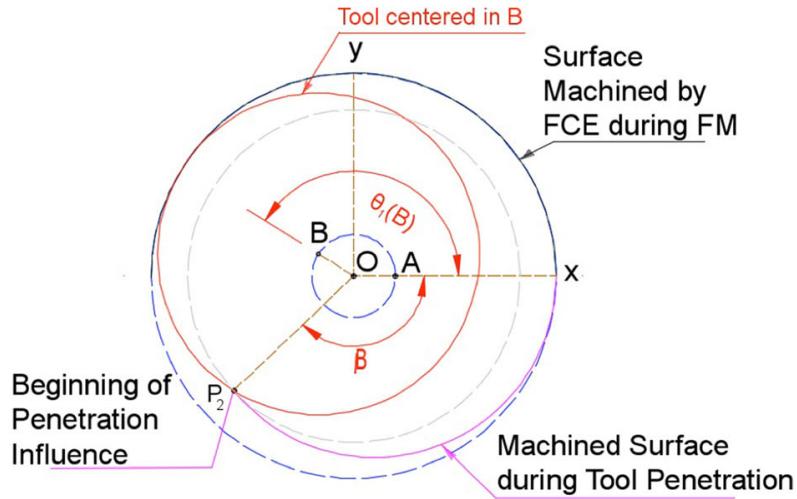

(c) Tool centered in B (end of steady state in full machining)

Fig. 2 Geometrical analysis of penetration influence on thread milling

of cut $r_{d o c}$, tooth working angle $\theta_{t w}$ and the projected feed per tooth $A A^{\prime}=f_{t x t}$. In steady state, the cutting edges cut regularly the same profile per revolution.

The feed per tooth projected in $x y$ plane is $f_{t x y}=$ $f_{t} /\left(\sqrt{\left(\frac{2 P}{\pi D_{t t}}\right)^{2}+1}\right)$. The number of revolutions that the tool spins around its axis $\left(\theta_{2}\right)$ is $D_{t t} \pi / f_{t x y}$.
The depth of cut $a_{d o c}(t)$ varies, so the flute engagement angle $\delta(t)$ and cutting continuity $c(t)$ [17] are described by Eq. 4, where $\lambda_{s t}$ is the tool helix angle and $\theta_{f}$ the angle between flutes [15].

$$
\begin{aligned}
\delta(t) & =2 \cdot a_{d o c}(t) \cdot \tan \left(\lambda_{s t}\right) / D_{t} \\
c(t) & =\left(\delta(t)+\theta_{t w}\right) / \theta_{f}
\end{aligned}
$$

The region influenced by tool penetration begins when the tool axis reaches the point $B$, as it can be observed in Fig. 2c. The angle that locates the tool axis position on the end of steady state, $\theta_{1}(B)$, is calculated by Eq. 6 .

$\theta_{1}(B)=2 \pi-\beta-\arccos \left(\frac{D_{t t}^{2}-D_{t}^{2}+D_{1}^{2}}{2 \cdot D_{1} \cdot D_{t t}}\right)$

\section{The mini-thread and tool geometry}

The analysis of tool penetration described by Section 2 is specially important in the case of mini-threads, in which there is not substantial gap between $D_{1}$ and $D_{t}$. In Fig. 1, the gap is shown in initial position when the tool and drilled hole are centralized in point $\mathrm{O}$. For small threads, the percentage of engagement $e \%$ is higher than regular cases:

$e \%=\frac{D-D_{1}}{D-D_{t}}$.

This study is focused on the manufacturing of M2 metric thread, the specific dimension used in internal threads for dental implants. Figure 3 shows the tool geometry for thread milling and Table 1 presents a complete panorama of geometrical parameters for the this case and it is detailed in this section:

- The value of $D_{t}$ is experimentally taken with Alicona Infinite Focus Measurement (IFM): $D_{t}=1.53 \pm 0.05$, slightly smaller then catalog dimension.

- Tool diameter is measured on the front cutting edge (Fig. 3a and b).

- The drilled diameter $D_{1}$ is also measured by IFM: $D_{1}=$ $1.61 \pm 0.05 \mathrm{~mm}$.

- The percentage of engagement is calculated as $85.1 \%$, which means the tool is very close to the drilled surface.

- The radial penetration when the tool is fully engaged during thread milling is $r_{p}^{\max }=\left(D-D_{1}\right) / 2=0.2$ $\mathrm{mm}$.

- The relation between pitch and tool diameter affects the radial depth of cut, $r_{d o c}=0.822 \mathrm{~mm}$, higher then milling tool radius, as a consequence, the tooth working angle $\theta_{t w}$ is $94.2^{\circ}\left(\theta_{t w}>90^{\circ}\right)$ [15].

- The thread milling tool helix angle (Fig. 3c) is $\lambda_{s t}=$ $15^{\circ}$ with three threaded cutting edges $\left(N_{f}=3\right.$ and 


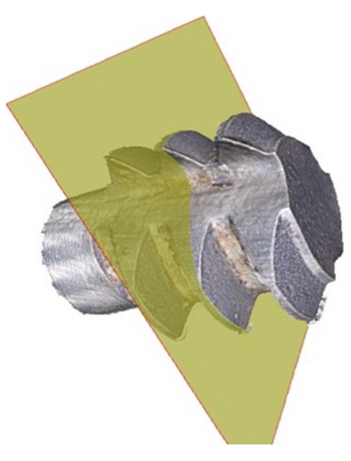

(a) Front Cutting Edge

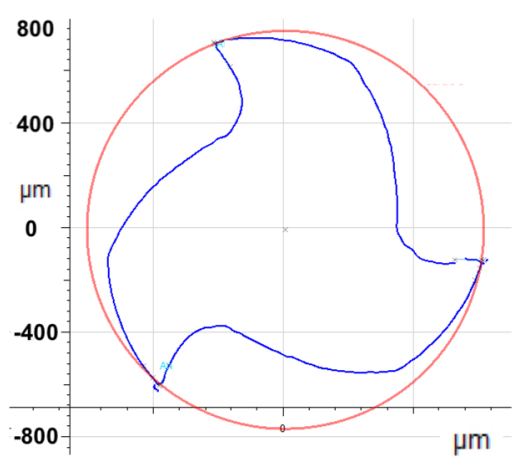

(b) Tool Diameter measured by IFM

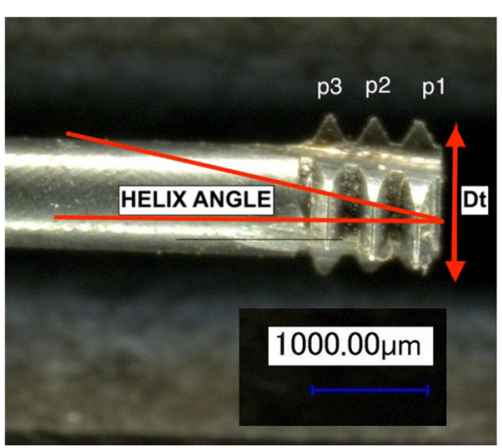

(c) Tool threads

Fig. 3 Mini-thread tool

$\theta_{f}=120^{\circ}$. Using this tool, each cutting edge can produce three thread pitches at the same time.

- The maximum depth of cut $a_{d o c}^{\max }$ is $1.2 \mathrm{~mm}$. The three tool pitches on the cutting edge are indicated by $p_{1}, p_{2}$ and $p_{3}$ in Fig. 1c.

- The engagement angle is: $\delta\left(t_{1}\right)=24^{\circ}$ and $\delta\left(t_{2}\right)=16^{\circ}$ and cutting continuity $c\left(t_{1}\right)=98 \%$ and $c\left(t_{2}\right)=92 \%$. As $c<1$, there is no simultaneous cutting flutes which allows a direct experimental force analysis on each flute.

- The angular position $Q$ is $\theta_{1}(Q)=-81.6^{\circ}$ and the angle between $\overline{O P_{2}}$ and $\overline{O A}$ is $\beta=132.1^{\circ}$. The tool position in the end of steady state é $\theta_{1}(B)=154.3^{\circ}$.

\section{Cutting conditions and experimental set-up}

This study includes a batch of thread milling experiments that it is the base of the methodology that is described in the next section. During experiments, the acquisition of cutting forces, tool spin angle, and tool position were developed while the thread are manufactured.

The machined material is a Cr-Co-based commercial dental alloy Romur 400, having the following chemical composition (\% weight): $62.5 \% \mathrm{Co}, 28.5 \% \mathrm{Cr}, 6.1 \% \mathrm{Mo}$, $0.55 \% \mathrm{Mn}$, and typical mechanical properties: $705 \mathrm{MPa}$ yield stress $(0.2 \%), 2.6 \%$ elongation in fracture, and 185 GPa elastic modulus.

Machining tests were performed in a 3 -axis milling center CNC DMC65V using water based emulsion. The drilling tool reference is MWS0160SB (Mitshubishi) and cutting parameters are: $V_{c}=10 \mathrm{~m} / \mathrm{min}$ and $f_{t}=0.01 \mathrm{~mm} / \mathrm{th}$. It was drilled $4 \mathrm{~mm}$ in depth. The thread milling tool is a H5087006-M2 (Walter Co) in solid carbide coated (TiCN) and cutting parameters were a constant cutting speed $V_{c}=20$ $\mathrm{m} / \mathrm{min}(N=4110 \mathrm{rpm})$ and two levels for feed per tooth: $f_{t}=0.025 \mathrm{~mm} / \mathrm{th} / \mathrm{rev}$ and $f_{t}=0.035 \mathrm{~mm} / \mathrm{th}$. Three cases of depth of cut were used: $a_{d o c}^{\max }=0.4,0.8$, and $1.2 \mathrm{~mm}$, meaning 1, 2 or 3 machined pitches in the workpiece.

The acquisition set-up (Fig. 4a) is composed of (1) a derivative electronic interface Heidenhain IBV 606 needed to acquire tool angular position from spindle encoder in a high band width, (2) a sensitive Kistler mini-dynamometer $9256 \mathrm{C} 2$ with (3) a signal amplifier 5019A, (4) the CNC machine analog output to acquire tool axis position $(x, y$ and $z$ ) and (5) a data acquisition card DAC 9188 (National Instruments - NI) using two modules 9215 for analogical signals and a trigger coupled to a digital module 9401 (NI) for encoder signals. The synchronous sampling is ensured thanks to this configuration. The sampling rate used in this case is $50 \mathrm{kHz}$. Dasylab software is used for data acquisition and Matlab software is used for data treatment and analysis.

The local interaction between the tool and the machined surface is described by the local forces $F_{r a d}$ and $F_{t a n}$, radial and tangent to the drilled surface. These components are calculated using $\theta_{1}$ and the dynamometer components $F_{x}$, $F_{y}$ and $F_{z}$, using Eq. 9. The resultant force $F_{r e s}$ is also calculated.

$$
\left[\begin{array}{c}
F_{\text {rad }} \\
F_{\text {tan }} \\
F_{z}
\end{array}\right]=\left[\begin{array}{ccc}
\cos \left(-\theta_{1}\right) & -\sin \left(-\theta_{1}\right) & 0 \\
\sin \left(-\theta_{1}\right) & \cos \left(-\theta_{1}\right) & 0 \\
0 & 0 & 1
\end{array}\right]\left[\begin{array}{l}
F_{x} \\
F_{y} \\
F_{z}
\end{array}\right]
$$

Table 1 Geometrical parameters calculated for M2 Dental Implants

\begin{tabular}{lllllllll}
\hline$D$ & $P$ & $D_{t}$ & $D_{t t}$ & $r_{p}^{\max }$ & $r_{d o c}$ & $\theta_{1}(Q)$ & $\beta$ & $\theta_{1}(B)$ \\
\hline $2 \mathrm{~mm}$ & $0.4 \mathrm{~mm}$ & $1.53 \mathrm{~mm}$ & $0.24 \mathrm{~mm}$ & $0.2 \mathrm{~mm}$ & $0.82 \mathrm{~mm}$ & $-81.6^{\circ}$ & $132.1^{\circ}$ & $154.3^{\circ}$ \\
\hline
\end{tabular}




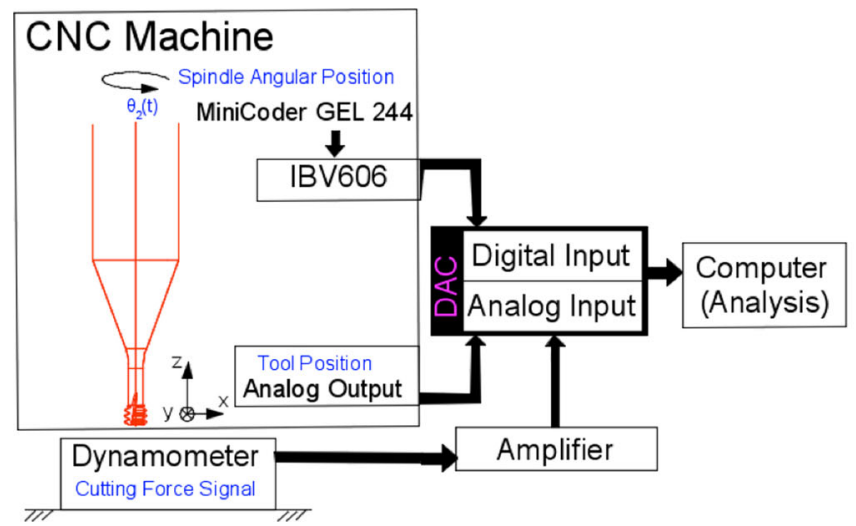

(a) Set-up for synchronous acquisition

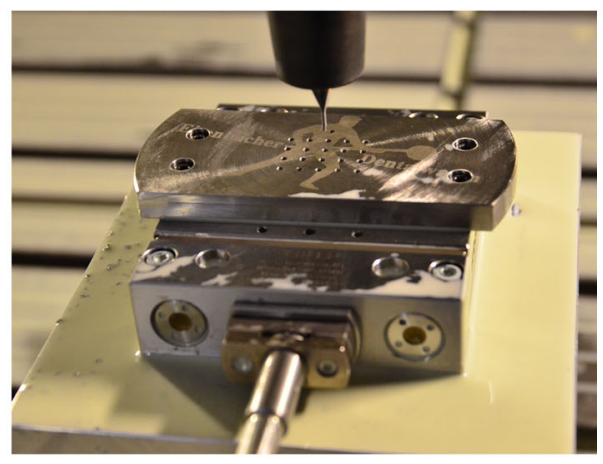

(b) Tool, Workpiece and Dynamometer

Fig. 4 Experimental set-up

\section{Methodology for calculating tool tip position using experimental data}

In order to calculate the tool tip trajectory considering tool deflection, it is proposed an hybrid procedure, illustrated in Fig. 5.

(a) In the first step, the CNC tool holder position $(x(t)$, $y(t))$ is taken from data file for each experiment. The trajectory is verified and $\theta_{1}$ is calculated as it is shown in Fig. 5a.

(b) On the second step, the tool stiffness is estimated by simulation, independent of the experimental results. The tool geometry is imported from experimental data (using STL technology) from IFM into a CAD software, Catia Software (Dassault systems).

A chosen force is applied on the cutting edge perpendicular to the tool axis. No vertical force is applied. The mechanical properties of Tungsten Carbide are used as input parameter on the software. It is considered the static deflection model, as the natural frequency is not included in harmonics of the experimental forces.

Five different values of the applied force (10 to $50 \mathrm{~N}$ ) are used on the simulations. Triangular linear elements are used on the simulations. For each cutting force, the tool tip displacement is registered and the global stiffness is calculated. Using this procedure, tool stiffness is $833 \mathrm{~N} / \mathrm{mm}$ (Fig. 5b).

(c) On the third step, the radial and tangential cutting forces are calculated (Eq. 9) using acquired cutting forces $\left(F_{x}, F_{y}\right)$ and $\theta_{1}$, based on $(x(t), y(t))$ measurements, for each experiment (Fig. 5c). (d) The last step calculates the tool tip trajectory considering the tool holder position, the forces applied on the tool and the tool stiffness. In real time, the displacement is calculated, as shown in Fig. 5d. The maximum tool deflection per tool spin revolution is analyzed.

\section{Results and discussions}

An extract of the results is presented in this section: cutting force results, tool tip deflection, and a comparison of the measured thread dimension with experimental results.

\subsection{Cutting force results}

Figure 6a presents the evolution of the resultant force along the variation of $\theta_{1}$. In that situation, the tool turns 20 revolutions during helical trajectory, meaning 60 teeth cuts as there are 3 flutes in this case. It can be seen the three stages of the average evolution of the forces: from 0 to $t_{1}$, it can be identified that tool penetration from $\theta_{1}(Q)<\theta_{1}<0$ and the increasing of forces; from $0<\theta_{1}<\theta_{1}(B)$ it is the part of full machining without influence of tool penetration, with constant force peaks and from $\theta_{1}(B)<\theta_{1}<360^{\circ}$, the influence of the tool penetration on the reduction of forces. It would be usual to have a linear decrease from $0^{\circ}$ to $360^{\circ}$, as the depth of cut reduces linearly. It is not the case, there is strong difference between the two stages after tool penetration. Specially on the last 15 revolutions, the amplitude reduces significantly due to tool penetration influence. 
Fig. 5 Procedure to estimate tool tip trajectory considering tool deflection
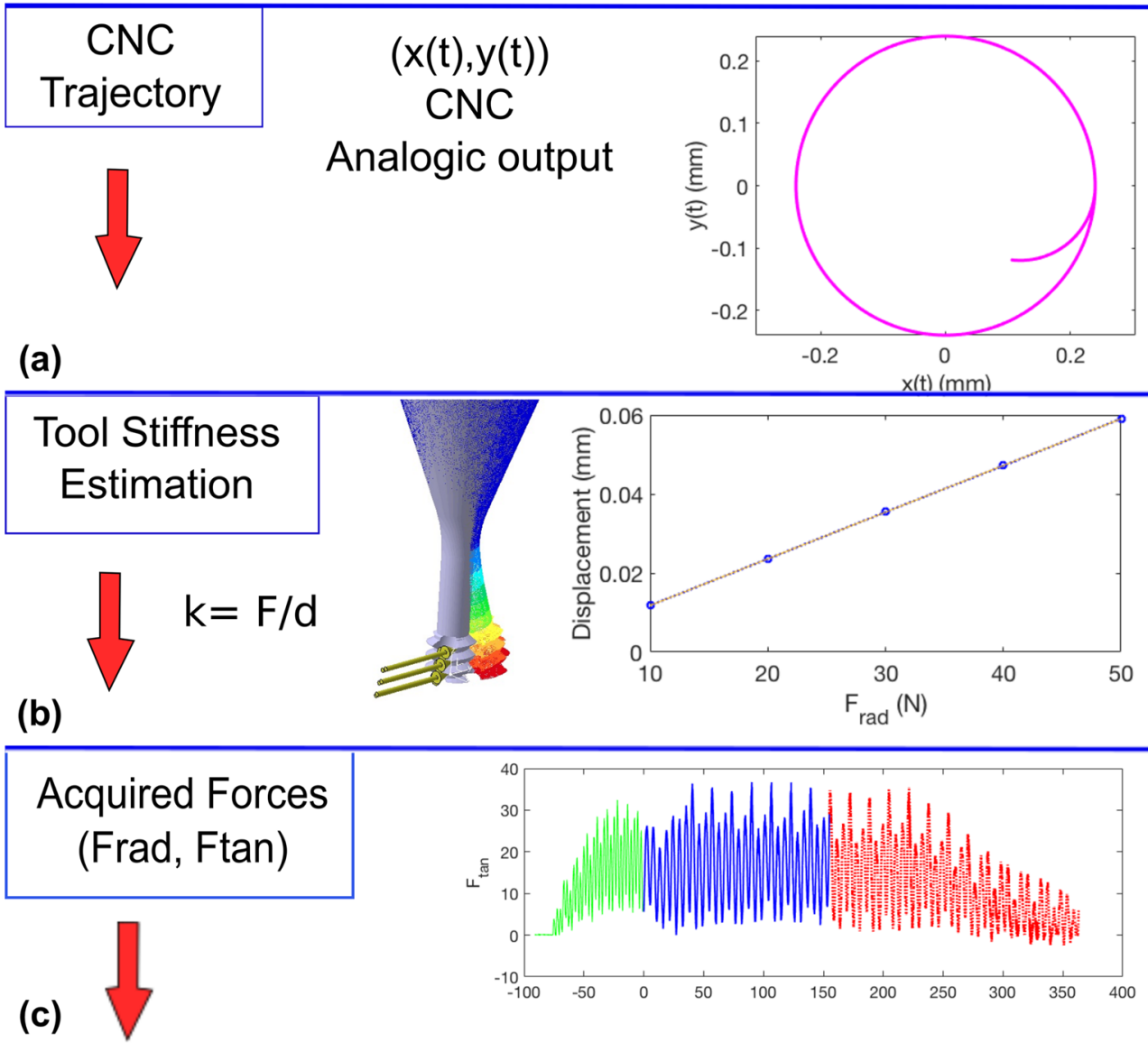

(d)

In Fig. 6b, the same evolution can be seen in tangential and radial components. These forces are important to analyze the deflection, specially in in radial direction because it reduces the engagement. In feed direction (tangential force) the component does not affect the thread geometry. Figure $6 \mathrm{c}$ presents a complete panorama of all the experiments, the force values show the average of thee peaks per revolution in each experiment.

\subsection{Tool tip deflection results}

The maximum tool deflection is calculated in each tool revolution using the described procedure. Figure 7 presents the

\section{$x(t)+F x / k$ \\ $y(t)+F y / k$}

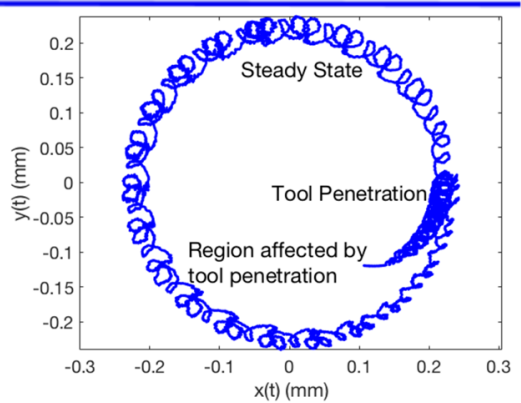

average of the maximum deflection for all experiments and the error bars represent the dispersion of the data. Introducing a constant radial correction on the tool trajectory (correction in $D_{t t}$ ), would not solve the problem because deflection is not constant. From Fig. 6, it can be noted that there is a big difference of the deflection for machining only one pitch which contribute to the recommendation of second pass for mini thread milling trajectory.

\subsection{Analysis of workpiece dimensions}

The workpiece is cut using wire-EDM process in order to measure the produced thread profiles in two $\theta_{1}$ positions: 


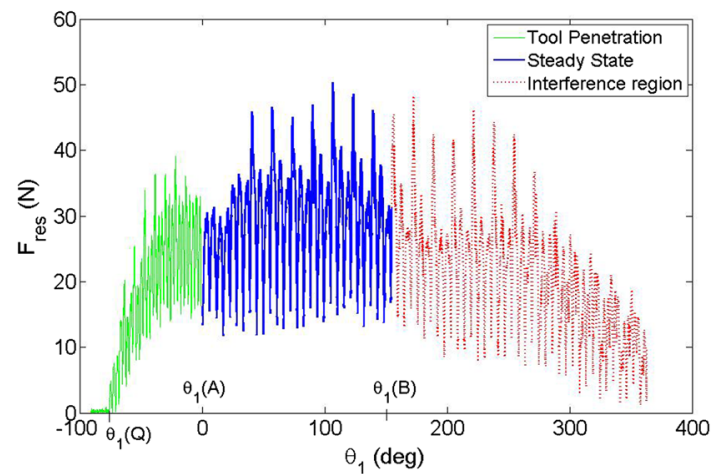

(a) Resultant force $(f t=0.025 \mathrm{~mm} / \mathrm{th} / \mathrm{rev})$

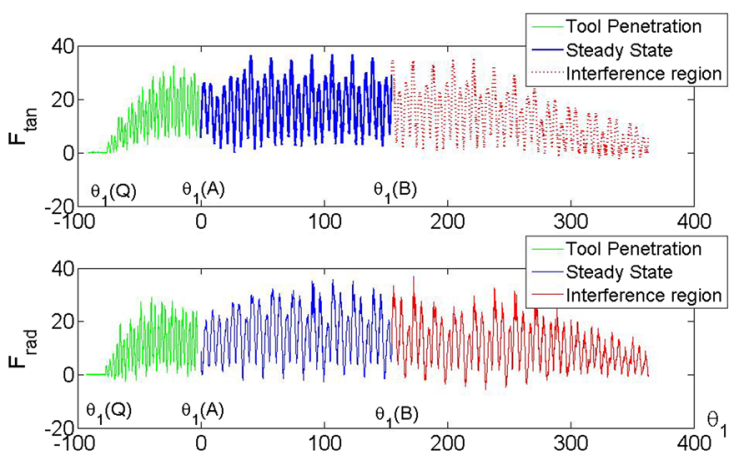

(b) Radial and tangential forces ( $f t=0.025$ $\mathrm{mm} / \mathrm{th} / \mathrm{rev}$ )

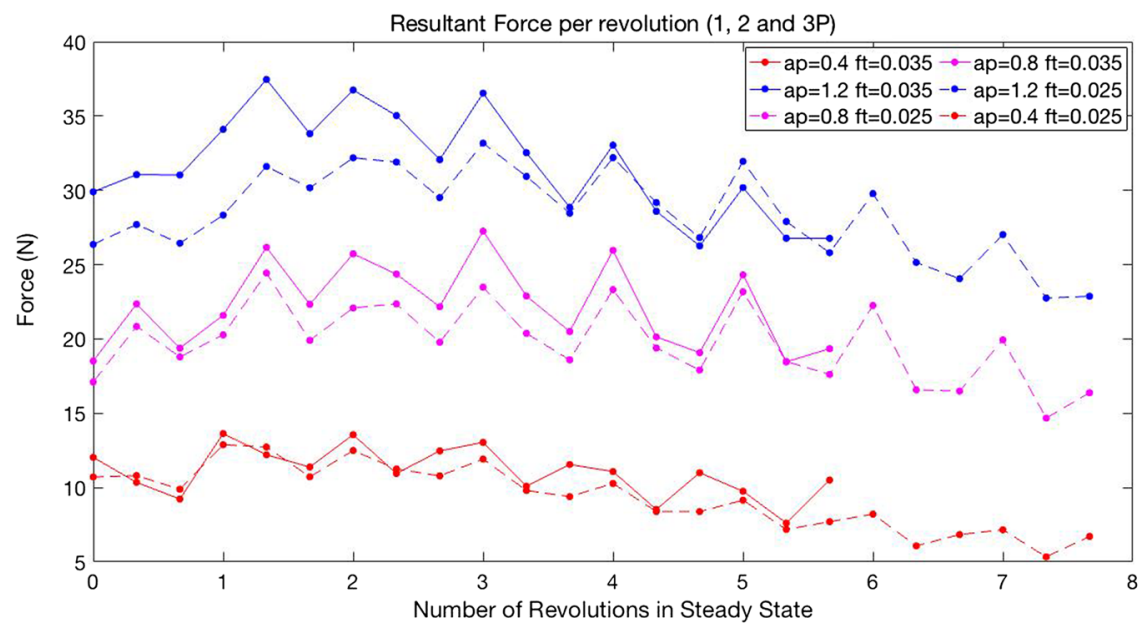

(c) Panorama of resultant forces for all experiments

Fig. 6 Experimental cutting forces

Fig. 7 Maximum tool tip deflection per revolution during full machining $(\mathrm{mm})$

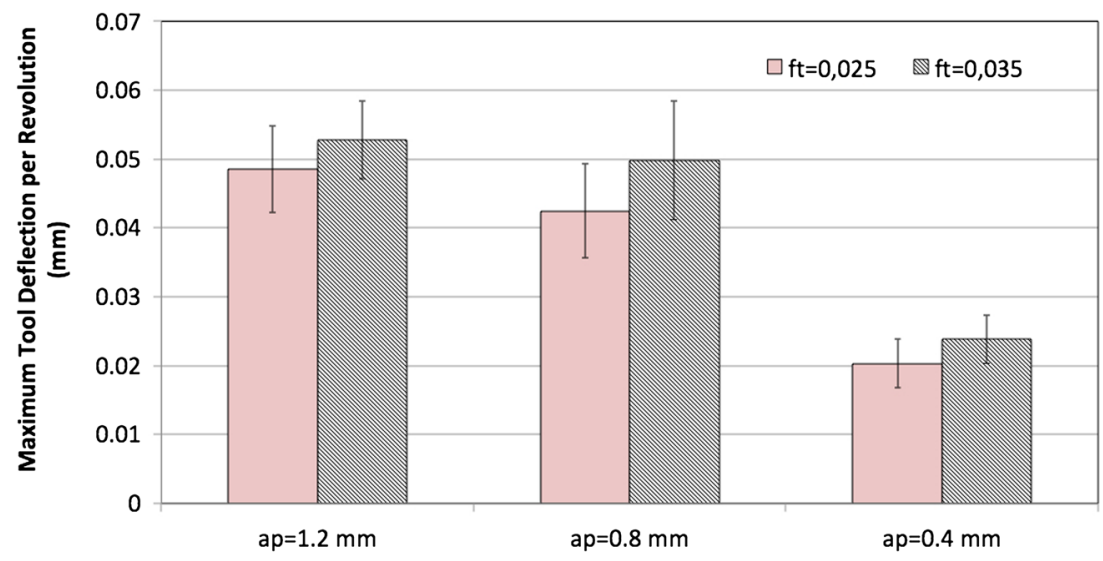




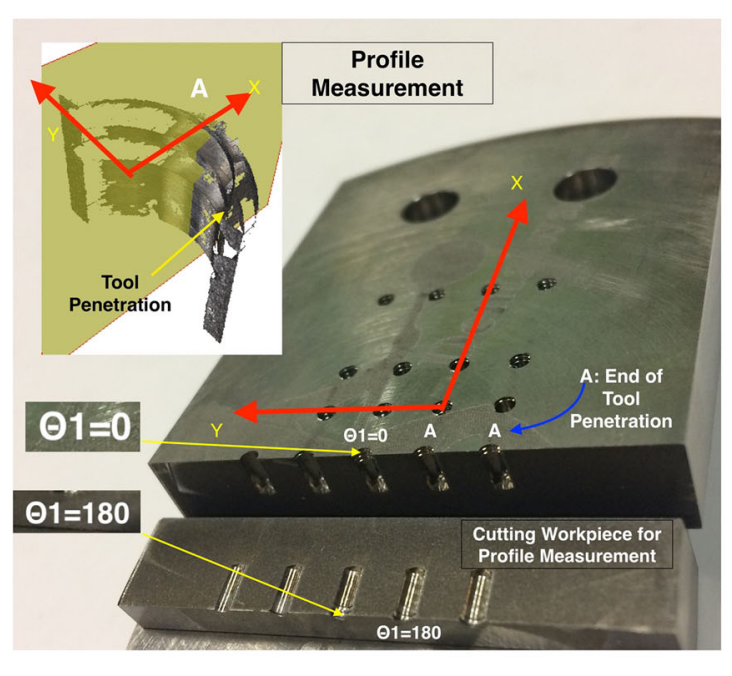

(a) Workpiece thread profile measurement in IFM

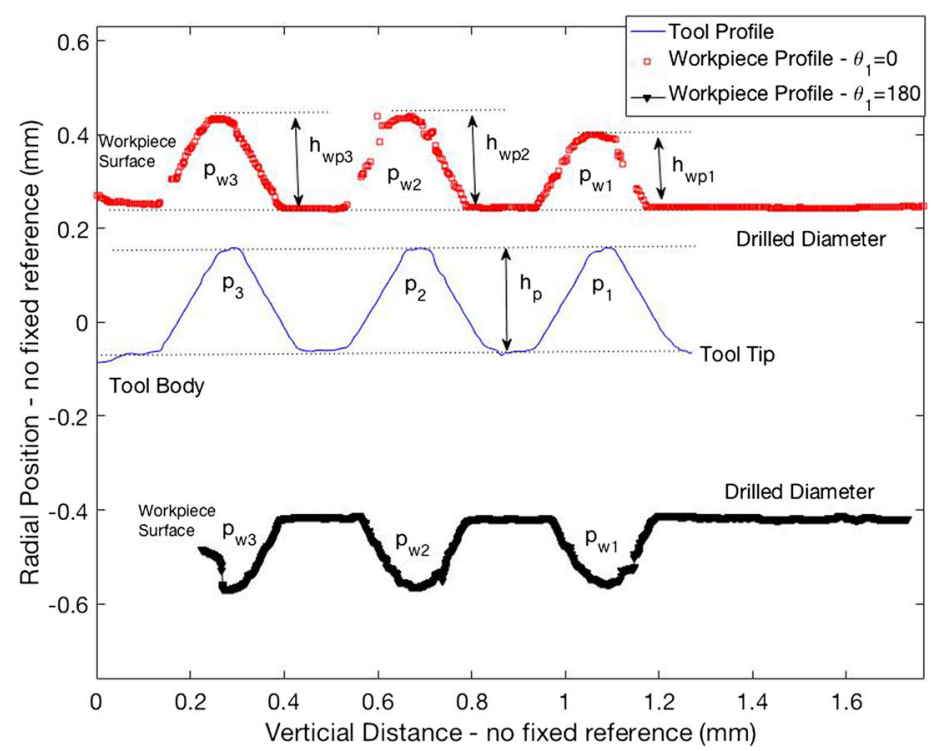

(b) Workpiece profiles in $\theta_{1}=0$ and $\theta_{1}=180^{\circ}$ and tool profile for reference

Fig. 8 Experimental data acquisition

$0^{\circ}$ and $180^{\circ}$. Figure $8 \mathrm{a}$ shows the cut workpiece and a image of the IFM measurement aligned with $\mathrm{x}$ direction. It is indicated the location machined when the tool is centered in $\mathrm{A}$, the end of tool penetration $\theta_{1}=0$ in one half of the workpiece. In the other half, $\theta_{1}=180^{\circ}$ is measured. The thread angle was measured in all threads (tool and workpiece) confirming the desired angle: $60 \pm 1^{\circ}$ (Fig. 8b).

The height of thread profile on the tool $h_{p}$ is measured $h_{p}=0.227 \pm 0.028 \mathrm{~mm}$ and it is confirmed that $h_{p}>r_{p}^{\max }$ $\left(r_{p}^{\max }=200 \mu \mathrm{m}\right)$. It allows to conclude that the thread milling tool did not machine the drilled surface $D_{1}$ (Fig. 8a) and that it can be taken as a reference in thread profiles on

Table 2 Results from IFM measurements: $\Delta r_{e x p}^{i}=r_{p}^{\max }-h_{w p}^{i}$

\begin{tabular}{llll}
\hline Number of pitches cut/position & $\Delta r_{\text {exp }}^{1}$ & $\Delta r_{\text {exp }}^{2}$ & $\Delta r_{\text {exp }}^{3}$ \\
\hline$n_{P}=1 / 0 \mathrm{deg}$ & $12.8 \mu \mathrm{m}$ & - & - \\
$n_{P}=1 / 180 \mathrm{deg}$ & $14.5 \mu \mathrm{m}$ & - & - \\
$n_{P}=2 / 0 \mathrm{deg}$ & $2.0 \mu \mathrm{m}^{*}$ & $29.9 \mu \mathrm{m}$ & - \\
$n_{P}=2 / 180 \mathrm{deg}$ & $29.3 \mu \mathrm{m}$ & $35.0 \mu \mathrm{m}$ & - \\
$n_{P}=3 / 0 \mathrm{deg}$ & $13.6 \mu \mathrm{m}^{*}$ & $15.3 \mu \mathrm{m}^{*}$ & $50.6 \mu \mathrm{m}$ \\
$n_{P}=3 / 180 \mathrm{deg}$ & $33.0 \mu \mathrm{m}$ & $38.7 \mu \mathrm{m}$ & $48.7 \mu \mathrm{m}$ \\
\hline
\end{tabular}

(*) two tool passes - see Fig. 8b the workpiece to measure $h_{w p}^{i}$ in order to calculate the $i$ front cutting edge (FCE) deflection $\Delta r_{\text {exp }}^{i}$ :

$\Delta r_{\text {exp }}^{i}=r_{p}^{\max }-h_{w p}^{i}$

Figure $8 \mathrm{~b}$ presents the workpiece profile taken on the thread manufactured using $n_{P}=3$ and $f_{t}=0.025 \mathrm{~mm} / \mathrm{th} / \mathrm{rev}$ experiment as well the tool profile for reference. From the thread height on the workpiece profile for the three FCE: $h_{w p}^{1}, h_{w p}^{2}$ and $h_{w p}^{3}$ in position $\theta_{1}=0$ and $\theta_{1}=180^{\circ}$. The results are presented in Table 2.

The results taken in position $\theta_{1}=0$ present lower values for the difference $\Delta_{\text {exp }}^{1}$ and $\Delta_{\exp }^{2}(*$ values in bold in Table 2). In this specific point, one cannot claim that this is the deflection because the tool machines twice this surface as the deflection reduces from $t_{1}$ to $t_{2}$, as it is represented in Fig. 9a and b. For all other values $\Delta r^{i}=200-h_{w p}^{i}(\mu m)$.

Considering ISO 965-1 standard, for M2x0.4 mm thread, to achieve tolerance $6 \mathrm{H}$ in the internal thread, the thread diameter could vary $90 \mu \mathrm{m}$, which means the $\Delta r_{\exp } \leq$ $45 \mu \mathrm{m}$ and for tolerance $5 \mathrm{H}, \Delta r_{\exp } \leq 35 \mu \mathrm{m}$. It can be claimed, as per results presented in Table 2, that manufactured threads are under tolerance $6 \mathrm{H}$. Values on the lower thread $\left(n_{P}=3\right)$ were neglected as the screw could not achieve this region as it is not completely machined. 


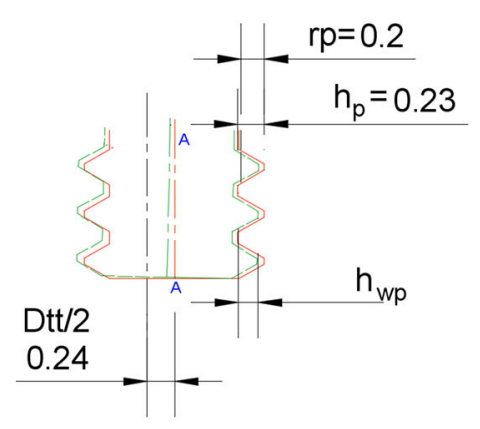

(a) Analysis of thread measurement

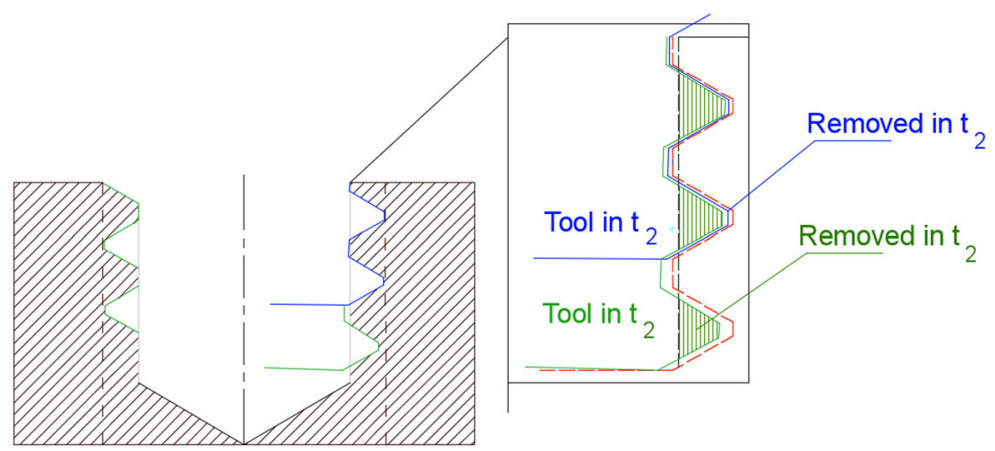

(b) Analysis of removed chip area in $\theta_{1}=0$ (in $t_{1}$ and $\left.t_{2}\right)$

Fig. 9 Analysis of the thread height and deflection

\section{Conclusions}

This article deals with milling process to manufacture mini-thread M2 in two dental materials. The geometry of the cutting related to the engagement between tool and workpiece was completely studied. The tool stages of tool penetration, steady state, and the region influenced by tool penetration were modeled analytically for any tool and thread dimension.

Experiments were developed in chrome-cobalt used in dental industry with: constant cutting speed and two levels for feed per tooth. Three levels for depth of cut were used machining at maximum 1,2 , or 3 thread at the same time, which means that the tool travels only one round in full machining as the tool have three pitches in each flute. During experiments, tool axis position and revolution was acquired to allow the computation of radial and tangential forces based on dynamometer signals. Deflection was estimated using tool stiffness and experimental cutting forces for all data points. The workpiece was cut and the thread height was measured in order to evaluate the quality of produced threads. It was noted that in the beginning of full machining, at $\theta_{1}=0$, in the first and second threads (from the top surface), the difference between the radial penetration and the measured thread height was lower because the tool re-machine the thread surface at this point. At $\theta_{1}=180^{\circ}$ it can be calculate the tool deflection influence on the thread height and determine the tolerance achieved.

Tool deflection is a consequence of forces proportional to geometrical tool engagement but, as it is not constant during the full thread machining, it cannot be compensated by a correction of the tool path radius. Future work could focus on the study of the tool geometry to prevent tool deflection. Also, micro surface quality of the thread could be introduced in the future analysis.
Publisher's Note Springer Nature remains neutral with regard to jurisdictional claims in published maps and institutional affiliations.

\section{References}

1. Elias CN, Fernandes DJ, Resende CR, Roestel J (2015) Mechanical properties, surface morphology and stability of a modified commercially pure high strength titanium alloy for dental implants. Dent Mater 31(2):e1

2. McCracken M (1999) Dental implant materials: commercially pure titanium and titanium alloys. J Prosthodont 8(1):40

3. Schwitalla AD, Zimmermann T, Spintig T, Abou-Emara M, Lackmann J, Maoller WD, Houshmand A (2018) Maximum insertion torque of a novel implant-abutment-interface design for peek dental implants. J Mech Behav Biomed Mater 77:85

4. Rittel D, Dorogoy A, Shemtov-Yona K (2017) Modelling dental implant extraction by pullout and torque procedures. J Mech Behav Biomed Mater 71:416

5. Rysava Z, Bruschi S, Carmignato S, Medeossi F, Savio E, Zanini F (2016) Micro-drilling and threading of the Ti6Al4V titanium alloy produced through additive manufacturing. Procedia CIRP 46:583. 7th HPC 2016 - CIRP conference on high performance cutting

6. Kuhn A, Iff TM, Cordey J, Baumgart F, Rahn B (1995) Bone deformation by thread-cutting and thread-forming cortex screws. Injury 26(Supplement 1):12

7. Zanger F, Sellmeier V, Klose J, Bartkowiak M, Schulze V (2017) Comparison of modeling methods to determine cutting tool profile for conventional and synchronized whirling. Procedia CIRP 58:222

8. Hernandez-Rodriguez M, Contreras-Hernandez G, JuarezHernandez A, Beltran-Ramirez B, Garcia-Sanchez E (2015) Failure analysis in a dental implant. Eng Fail Anal 57:236

9. Wu SW, Lee CC, Fu PY, Lin SC (2012) The effects of flute shape and thread profile on the insertion torque and primary stability of dental implants. Med Eng Phys 34(7):797

10. Hasan I, Roger B, Heinemann F, Keilig L, Bourauel C (2012) Influence of abutment design on the success of immediately loaded dental implants: experimental and numerical studies. Med Eng Phys 34(7):817

11. Khoshdarregi MR, Altintas Y (2015) Generalized modeling of chip geometry and cutting forces in multi-point thread turning. Int J Mach Tools Manuf 98:21 
12. Fromentin G, Dobbeler B, Lung D (2015) Computerized simulation of interference in thread milling of non-symmetric thread profiles. Procedia CIRP 31:496

13. Fromentin G, Poulachon G (2010) Geometrical analysis of thread milling - part 1: evaluation of tool angles. Int J Adv Manuf Technol 49(1):73

14. Fromentin G, Poulachon G (2010) Geometrical analysis of thread milling - part 2: calculation of uncut chip thickness. Int J Adv Manuf Technol 49(1):81

15. Araujo AC, Fromentin G, Poulachon G (2013) Analytical and experimental investigations on thread milling forces in titanium alloy. Int J Mach Tools Manuf 67:28

16. Wan M, Altintas Y (2014) Mechanics and dynamics of thread milling process. Int J Mach Tools Manuf 87:16
17. Araujo AC, Fromentin G (2017) Modeling thread milling forces in mini-hole in dental metallic materials. Procedia CIRP 58:623

18. Araujo AC, Silveira JL, Jun MB, Kapoor SG, DeVor R (2006) A model for thread milling cutting forces. Int J Mach Tools Manuf 46(15):2057

19. Fromentin G, Sharma VS, Poulachon G, Paire Y, Brendlen R (2011) Effect of thread milling penetration strategies on the dimensional accuracy. ASME J Man Sci Eng 133(4)

20. Sharma V, Fromentin G, Poulachon G, Brendlen R (2014) Investigation of tool geometry effect and penetration strategies on cutting forces during thread milling. Int $\mathrm{J}$ Adv Manuf Technol 913-919 